\title{
BACTRIM 'Roche' EN EL TRATAMIENTO DE LA CISTITIS
}

\author{
Univérsitas Médica - Vol. XIV - № 1 - 1972
}

Dadia la importancia y la frecuencia de la Crisis infecciosa en la práctica urológica y las múltiples fallas que se han presentado en el tratamiento de dicha entidad con diferentes agentes antibacterianos, nos hemos propuesto evaluar la efectividad clínica de un nuevo agente antimicrobiano que consiste en la asociación de $80 \mathrm{mg}$. de TRIMETOPRIM (TM) y 400 mg. de SULFAMETOXAZOL (ZMZ) (BACTRIM 'Roche').

Esta evaluación fue llevada a cabo en el Hospital San Ignacio de Bogotá en pacientes del sexo femenino y en las cuales se descartó obstrucción urinaria baja, por medios endoscópicos o radiológicos.

\section{Material y Métodos}

Fueron estudiadas 20 pacientes en las cuales se demostró la ausencia de obstrucción baja y que presentaban la tríada sintomática de polaquiuria, disuria y nicturia y que al estudio endoscópico se demostró la presencia de cistitis. Cada una de las pacientes con sospecha de infección urinaria baja fue sometida al siguiente estudio:

1. Historia clínica detallada.

2. Estudio microscópico del sedimento urinario.

3. Urocultivo con recuento de colonias.

4. Calibración de la uretra por medio de las bujías de bola.

5. Estudio endoscópico de todos los pacientes, antes y después del tratormiento.

6. Ocasionalmente se practicaron estudios radiológicos como la Cistouretrografía miccional como medio para evaluar el diámetro uretral y el cuello vesical, en vista de la duda que en ocasiones se presentó con las bujías calibradoras.

Una vez demostrada la presencia de infección urinaria por medios clínicos y para-clínicos, se procedió a la calificación uretral con las bujías de bola de Otis. De inmediato se practicó la endoscopia comprobándose mediante visión directa la infección en la vejiga. Cabe anotar que pacientes 
con cualquier defecto anatómico encontrado, fueron descartadas del presente trabajo.

Se procedió a formular a las pacientes con BACTRIM, todas las cuales recibieron como dosis dos tabletas tres veces al día por una semana; al cabo de la semana se dejaron sin droga por cuatro días y se les tomó un urocultivo nuevo con recuento de colonias y se controlaron bajo visión directa con endoscopia.

Los 20 casos estudiados pertenecen al sexo femenino y sus edades oscilan entre los 32 y 46 años, o sea, 39 años promedio. La naturaleza de la enfermedad fue considerada como aguda en siete de los veinte casos $(35 \%)$; los trece restantes se consideraron como crónicos (65\%).

En las pacientes estudiadas no se tomó en cuenta la sensibilidad "invitro" a la droga.

Los resultados del urocultivo en cada una de las pacientes puede resumirse así:

Diez pacientes $(50 \%)$ presentaron un recuento de colonias de más de un millón de E. Coli.

Siete pacientes (35\%) presentaron un recuento de colonias de más de un millón de Proteus Vulgaris.

Tres pacientes (15\%) presentaron al urocultivo entre ochocientos mil y un millón de colonias de Estreptococo Betahemolítico.

Catorce de las veinte pacientes estudiadas (70\%) presentaban flujo vaginal de tipo tricomonas por su aspecto y para lo cual se enviaron, posteriormente, al servicio de ginecología. El estado nutricional de todas las pacientes, a excepción de una, puede calificarse como bueno.

\section{Resultados}

En los 19 de los 20 casos estudiados y en los cuales se le inició terapia antimicrobiana con BACTRIM disminuyeron en su sintomatología aproximadamente al cuarto día y se sintieron sin ninguna alteración urinaria al cabo del séptimo día, menos una paciente en la que la mejoría nunca se efectuó y para la cual se están practicando estudios investigativos de Tuberculosis urinaria.

Los resultados para-clínicos, después del tratamiento, fueron los siguientes:

Doce pacientes (60\%) les fue encontrado el urocultivo negativo.

Siete pacientes (35\%) mostraron colonias que en su recuento fueron menores de 60.000 por CC. De estas siete pacientes, cuatro (57\%) mostraron aún la presencia de Proteus Vulgaris; en las otras tres (43\%) se encontró estafilococo aureus coagulosa positivo que se interpretó como reinfección y a las cuales se les continuó el tratamiento por una semana más, al cabo de la cual, se negativizaron. 
Una paciente $(5 \%)$ presentó su urocultivo negativo, pero persistió la sintomatología urinaria. Como su estado nutricional no era adecuado se procedió a investigar Tuberculosis en él.

Una vez tenidos los resultados anteriores, a todas las pacientes se les practicó endoscopia encontrándose a la visión directa una notable mejoría en las alteraciones de la mucosa vesical.

Como efectos secundarios fueron encontrados los siguientes:

Cuatro pacientes $(20 \%)$ no presentaron ninguna alteración al estar tomando la droga.

Cuatro pacientes $(20 \%)$ presentaron vómito entre el segundo y cuarto día del tratamiento, desapareciendo en los siguientes días.

Seis pacientes $(30 \%)$ presentaron mareos que fueron interpretados como sin importancia por los mismos.

Cinco pacientes (25\%) presentaron sudoración profusa media hora después de tomar la droga. La sudoración desapareció al cabo del cuarto día del tratamiento.

Diecinueve de las veinte pacientes se mostraron satisfechas por la efectividad de la droga.

\section{Discusión}

Continúa comprobándose el predominio de la infección urinaria en pacientes del sexo femenino. En nuestro estudio el $100 \%$ de los casos pertenece a dicho sexo. La explicación de este hecho parece seguir siendo la cortedad de la uretra femenina y la contaminación ascendente. Algunos explican esto por una mayor amplitud del esfínter interno de la vejiga (Forsythe).

Es importante anotar la relevancia que tuvo la cistouretrografía para demostrar un número de anomalías que por otro medio sería casi imposible demostrar. En nuestro estudio tuvimos que practicársela a tres pacientes $(15 \%)$ en las cuales teníamos dudas al respecto de lesiones uretrales tipo obstrucción a igual que de cuello vesical.

Se debe recordar nuevamente que la evolución y el pronóstico de la infección urinaria depende de factores como la edad de comienzo, el tiempo transcurrido hasta el diagnóstico y el tipo de tratamiento establecido que en nuestro caso resultó ampliamente satisfactorio.

\section{Efectividad terapéutica}

Tratamos de evaluar la efectividad del nuevo producto de Laboratorios Roche denominado genéricamente como la asociación de $80 \mathrm{mg}$. de TRIMETOPRIM con $400 \mathrm{mg}$. de una sulfa, el SULFAMETOXAZOL (BACTRIM) en las infecciones vesicales cuya causa no sea de origen obstructivo. La manera objetiva de hacerlo es evidentemente la desaparición de la sintomatología y la curación comprobada por medios para-clínicos y con 
la ayuda definitiva de la endoscopia. Recordamos que todas las pacientes analizadas en el presente estudio llegaron a la consulta con la tríada sintomática de disuria, polaquiuria y nicturia y que al cabo del tratamiento con BACTRIM pudimos comprobar que la sintomatología había desaparecido en el $95 \%$ de los casos y que a la visión directa por medios endoscópicos, los cambios patológicos observados en la pared vesical, antes del tratamiento, habían desaparecido.

Si tenemos en cuenta que trece pacientes habían sido tratadas en otros consultorios y que la efectividad terapéutica de otros productos no pudo demostrarse, estas pacientes que fueron colocadas en campo de la cronicidad en su enfermedad y que una vez que recibieron las dosis utilizadas en nuestro trabajo de BACTRIM presentaron curación tanto de su sintomatología, como de su lesión vesical, debemos concluir que la efectividad terapéutica del BACTRIM es óptima. Si le sumamos las seis pacientes que se llevaron al campo de la sintomatología aguda en su enfermedad y que presentaron curación, se concluye que el nuevo producto es altamente beneficioso para el tratamiento de Cistitis de origen no obstructivo.

\section{Resumen}

Fueron tratadas 20 pacientes pertenecientes al sexo femenino con Cistitis comprobada por medios clínicos, para-clínicos y bajo visión directa por medio de la endoscopia urológica.

Se utilizó un nuevo producto compuesto por la asociación de $80 \mathrm{mg}$. de Trimetoprim y 400 mg. de Sulfametoxazol (BACTRIM 'Roche'), suministrado por vía oral y en las dossi de dos tabletas tres veces al día por una semana. Los resultados fueron satisfactorios en el 95\% de los casos, considerándose a las pacientes curadas al fin del tratamianto.

Las pacientes fueron seleccionadas descartándose cualquier origen obstructivo. 